\title{
A Novel Cytotoxic Alkaloid of Lamellarin Class from a Marine Ascidian Didemnum sp.
}

\author{
Jungyeob Ham and Heonjoong Kang ${ }^{\star}$ \\ Marine Biotechnologv Laboratory and Research Institute of Ocemographw, School of Earth and Emironmental Sciences, \\ Seoul National Lniversity, San 56-1 Shinlim-Dong Kwanck-Ku, Seoul 151-7+7, Korea \\ Received November 5, 2001
}

Keywords : Lamellarin Marine ascidian, Cytotoxicity , Alkaloid, Natural products.

Many structurally and pharmacologically novel natural products have been isolated to date from a variety of species of marine ascidians, invertebrate chordates (phy lum Chordata. subphylum Urochordata, class Ascidiacea). Major secondary metabolites of ascidians are amino acid-derived compounds. ${ }^{1}$ In the chemistry of the genus Didemntm, tyrosine and tryptophan are the najor anino acid conmonents. ${ }^{2}$ Lamellarins. isolated originally from prosobranch mollusc Lamellaria sp. ${ }^{3}$ and later from the ascidian $D$. chartacetm ${ }^{4.5}$ the sponge Dendrilla cactos. ${ }^{6.7}$ unidentified Didemntm sp. ${ }^{8.5}$ and a species of unidentified ascidian. ${ }^{[0.11}$ are presumably condensation products of 3-(3,4-dilhydroxyphenyl) alanines (or 3hydroxytyrosines. viz DOPA's) ${ }^{12}$ and showed various bioactivities, such as cy totoxicity ${ }^{3.13 .14}$ ummumomodulating activity. ${ }^{8}$ HIV integrase-inhibitory activity. ${ }^{11}$

We studied a purple unidentified Didemnum sp. (other than $D$. chartaceum) to search for novel cytotoxic compounds. In this paper, we describe the structure elucidation of lamellarin $\beta$ (1) using spectroscopic methods including the extensive use of 2-dimensional NMR correlation experiments. Molecular modeling study of the alkaloid was also conducted. The issue of chirality and the shielding effect of phenyl rings are discussed.

The specimens were lyophilized and extracted twice each with $70 \%$ methanolic chloroform and methanol. The combined extract was concentrated under vacuum and fractionated between hexane and methanol. The methanol-soluble material was further partitioned between ethyl acetate and water. The ethyl acetate fraction showed cytotoxicity against human acute promyelocytic leukemia cells (HL-60). Bioactivityguided separation of the ethyl acetate-soluble material through Sephadex LH-20 (MeOH), followed by chromatography on reversed-phase HPLC (ODS-silica), gave a cy tototoxic compound. lamellarin $\beta$ (1). along with known compounds. lamellarins $\mathrm{G}(\mathbf{2})^{\dagger}$ and $\mathrm{L}(\mathbf{3})^{\S}$

\section{Experimental Section}

Instruments and Data Collection. Low and high resolution mass measurements of DEI and FAB were supplied by the Mass Spec. Facility at the Scripps Research Institute. La Jolla. California. USA Optical rotations were measured on a Roudolf polarimeter with a $10-\mathrm{cm}$ cell. Infrared spectra were recorded on a Perkin Elmer FT-IR spectrophotometer Model 1600 and ultraviolet spectra on a Perkin Elmer Model Lambda 3B.
NMR spectra were recorded at Varian 400 and $500 \mathrm{MHz}$ and Bnuker 200. 300. and $500 \mathrm{MHz}$ instruments. Double Quantum Filtered Correlation Spectroscopy (DQFCOSY). ${ }^{15}$ Nuclear Overhauser Exchange Correlation Spectroscopy (NOESY). ${ }^{16}{ }^{1} \mathrm{H}-$ detected Heteronuclear Multiple-Quantunn ${ }^{1} \mathrm{H}-$ ${ }^{13} \mathrm{C}$ Coherence (HMQC) ${ }^{17}$ and ${ }^{1} \mathrm{H}$-detected Heteronuclear Multiple-Bond ${ }^{1} \mathrm{H}^{13}{ }^{13} \mathrm{C}$ Correlation $(\mathrm{HMBC})^{18}$ experiments were performed using a Varian UN-500 spectrometer. A Brucker WP-200SY spectrometer was used for ${ }^{13} \mathrm{C}$ experiment. All chemical shifts were reported with respect to TMS $(\delta 0)$. Typical dl delay of $0.7 \mathrm{sec}$ was used for the DQFCOSY experiment. For the NOESY experiment. $3 \mathrm{sec}$ $\mathrm{dl}$ delay and $800 \mathrm{msec}$ mixing time were utilized. The homonuclear 2-dimensional NMR spectra were acquired and processed in phase-sensitive modes. such as phase $=1,2$ or 3. Both Gaussian and sine bell functions were used for weighting. HMBC experiment was optimized at $160 \mathrm{~Hz}$ for the compounds to suppress ${ }^{1} J_{\mathrm{CH}}$ couplings. Typical $\mathrm{dl}$ delay of $1.0 \mathrm{sec}$ was utilized for the proton-detected heteronuclear 2-dimensional NMR experiments. For processing of those spectra. sine bell and Gaussian weighting functions were used for $\mathrm{HMBC}$ and $\mathrm{HMQC}$ experiments. respectively.

Collection, Extraction, and Isolation. The purple encrusting ascidian. Didemntm sp., collected in the Indian Ocean. was kindly provided by Professor Fenical at the Scripps Institution of Oceanography. La Jolla. USA. The specimens were kept frozen at $-20^{\circ} \mathrm{C}$ until use. The lyophilized animal ( $74 \mathrm{~g}$. dry weight) was extracted twice each with $70 \% \mathrm{MeOH} /$ $\mathrm{CHCl}_{3}$ and methanol. The combined extract was concentrated and partitioned between hexane and methanol. The methanol-soluble material was further partitioned between ethyl acetate and water. Gel-filtration of the ethyl acetatesolubles through Sephadex LH-20 and Spectra Gel HW-40 with methanol gave several fractions which contained lamellarins $\beta$ (1). G (2) and $L(3)$. Further purification of alkaloids $1-3$ was accomplished by reversed-phase HPLC (ODS-silica) in combination with bioassay: To purify compound $1,30 \% \mathrm{CH}_{3} \mathrm{CN}$ in $0.1 \%$ trifluoroacetic acid was used as the eluting solvent. Yields of compounds $1-3$ were $10 \mathrm{mg}$. $5 \mathrm{mg}$. and $8 \mathrm{mg}$. respectively

Lamellarin $\beta$ (1): an amorphous solid: $[\alpha]_{\mathrm{D}}=0^{\circ}$. HRDEIMS: $\mathrm{M}^{-}$obsd. $m z 473.1094, \mathrm{C}_{26} \mathrm{H}_{19} \mathrm{NO}_{8}$ dev. -3.5 ppm: UV (MeOH) $\lambda_{\max }: 336 \mathrm{rm}(\varepsilon 17000), 315(17000)$. 278 (23000). 268 (sh). 205 (43000): UV (MeOH $+\mathrm{NaOH})$ $\lambda_{\text {max }}: 362 \mathrm{lum}(\varepsilon 15800) .322$ (17600). 287 (23000), 205 (60000): IR (NaCl) $v_{\max }: 3700-3000,1690,1595,1420$. 
$1285,1250,1187 \mathrm{~cm}^{-1}$

Molecular Modeling Study. Energy minimization of 1 was performed using a Serena software. penodel, which adopts a MMX force field. The actual presentation of 1 (Figure 2) was obtained using a combination of a Chen 3D program and a ChemDraw software released from the Cambridge Scientific Computing. Inc.

Cytotoxictiy Assay. Human acute promyelocytic leukenia cells (HL-60) were grown in RPMI 1640 with $10 \%$ fetal bovine serum in $5 \% \mathrm{CO}_{2}$ atmosphere. Cytotoxicity of crude extract and subsequently purified compounds were tested against this cell line according to Mosmann's method. colorimetric MTT assay. ${ }^{19}$

Preparation of Acetate Derivative 1a. Acetic anhydride $(0.1 \mathrm{~mL})$ was added to a solution of alkaloid $(1 \mathrm{mg})$ in pyridine $(0.2 \mathrm{~mL})$ and stirred for 3 hours at room temperature. The reaction was monitored by TLC. Reagents were evaporated under high vacuum and partitioned sequentially between ethyl acetate and ice water. between ethyl acetate and $0.1 \mathrm{NaHCO}_{3}$ solution, and between ethyl acetate and brime. Finally, the product was dried with $\mathrm{MgSO}_{4}$ and filtered. The solvent was evaporated under vacuum to give the acetate derivative (1a) quantitatively

Pentaacetate 1a: an amorphous solid: $[\alpha]_{\mathrm{D}}=0^{\circ}$; LRFABMS, $(\mathrm{M}+\mathrm{H})^{-}$obsd. $m z$ 684. $(\mathrm{M}+\mathrm{Cs})^{-} \mathrm{m} / \mathrm{z}$ 816: HRFABMS. $(\mathrm{M}+\mathrm{Cs})^{-}$obsd. $m z 816.0693 . \mathrm{C}_{36} \mathrm{H}_{39} \mathrm{NO}_{13} \mathrm{Cs}$, dev. $4.0 \mathrm{ppm}$ $(3.3 \mathrm{mmul}) ;{ }^{1} \mathrm{H}$ NMR $\left(500 \mathrm{MHz} . \mathrm{CDCl}_{3}\right): \delta 2.20$ (s. $3 \mathrm{H}$ ). 2.23 (s. 3H), 2.28 (s. $3 \mathrm{H}), 2.29(\mathrm{~s}, 3 \mathrm{H}), 2.3 \mathrm{l}(\mathrm{s}, 3 \mathrm{H}), 3.12$ (m. lH). $3.20(\mathrm{~m}, 1 \mathrm{H}) .4 .53(\mathrm{~m} . \mathrm{lH}) .5 .12(\mathrm{~m} . \mathrm{HH}) .6 .85(\mathrm{~s} . \mathrm{H})$. $7.11(\mathrm{~s}, 1 \mathrm{H}), 7.12$ (s. IH), 7.13 (s, IH). 7.17 (d. IH. $J=2$ Hz). $7.2 \mathrm{l}(\mathrm{dd}, \mathrm{lH} . J=8,2) .7 .24(\mathrm{~d}, 1 \mathrm{H}, J=8)$.

\section{Results and Discussion}

Structure Elucidation of the Lamellarin. Lamellarin $\beta$ (1. Table 1) was obtained as an amorphous solid. The high resolution desorption electron ionization mass spectrometry (HRDEIMS) established its molecular formula as $\mathrm{C}_{66} \mathrm{H}_{1} \mathrm{NO}_{8}$ [obsd. $m z+73.1094 \mathrm{M}^{+}$. dev. $-3.5 \mathrm{ppm}$ ]. The high degree of unsaturation (18 degrees) was evident from the molecular formula. and also supported by its UV spectrum $[(\mathrm{MeOH})$ $\lambda_{\text {max }}: 336(\varepsilon 17000), 315(17000), 278(22000), 265(\mathrm{sh})$. and $205(43000) \mathrm{rm}]$. A bathochronic shift ( $\mathrm{IN} \mathrm{NaOH}$ ), a broad and strong IR absorption band at $3700-3000 \mathrm{~cm}^{-1}$, and ${ }^{13} \mathrm{C}$ NMR data (8 signals downfield of $\delta 140$ ) suggested the phenolic nature of the compound. A conjugated ester functional group was present. which was indicated by a strong IR band at $1690 \mathrm{~cm}^{-1}$ in combination with a carbon signal at $\delta$ 154.4.

The proton NMR spectrum of compound 1 showed seven aromatic signals and two mutually coupled methylene resonances $[\delta 2.93$ (t. $2 \mathrm{H}, J=7 \mathrm{~Hz}) .4 .54(\mathrm{dt}, 1 \mathrm{H}, J=13.5 .7 \mathrm{~Hz}$ ). and $4.57(\mathrm{dt}, 1 \mathrm{H}, J=13.5,7 \mathrm{~Hz})]$. Among the aromatic signals, a 1.2,4-trisubstituted benzene ring was very obvious from analysis of coupling constants $[\delta 6.74$ (dd, $1 \mathrm{H}, J=8,2$ $\mathrm{Hz}) .6 .73(\mathrm{~d}, 1 \mathrm{H}, J=2 \mathrm{~Hz}$ ), and $7.07(\mathrm{~d}, 1 \mathrm{H} . J=8 \mathrm{~Hz})]$. Four aromatic singlets either came from four different spin systems
Table 1. NMR Assignments for Lamellarin $\beta(1)$

\begin{tabular}{|c|c|c|c|}
\hline no & ${ }^{13} \mathrm{C}^{\mathrm{d}}$ & $\mathrm{HMBC}(8 \mathrm{~Hz})^{4}$ & NOESY $Y^{b}$ \\
\hline 1 & 154.4 & & \\
\hline 2 & 112.2 & & \\
\hline 3 & 127.5 & & \\
\hline 4 & 108.9 & & \\
\hline 5 & 146.2 & & \\
\hline 6 & $103.26 .72(\mathrm{~s}, \mathrm{lH})$ & $\mathrm{C} 4, \mathrm{C} 5, \mathrm{C} 7, \mathrm{C} 8$ & \\
\hline 7 & 144.7 & & \\
\hline 8 & 142.1 & & \\
\hline 9 & $108.56 .46(\mathrm{~s}, \mathrm{lH})$ & $\mathrm{C} 3, \mathrm{C} 5, \mathrm{C} 7, \mathrm{C} 8$ & $\mathrm{H} 21, \mathrm{H} 25$ \\
\hline 10 & $\begin{aligned} 42.04 .54(\mathrm{dt}, 1 \mathrm{IH}, J & =13.5,7 \mathrm{~Hz}) \\
4.57(\mathrm{dt}, 1 \mathrm{IH}, J & =13.5,7)\end{aligned}$ & $\begin{array}{l}\mathrm{C} 2, \mathrm{Cl1}, \mathrm{C} 12 \\
\mathrm{C} 18\end{array}$ & $\mathrm{Hll}$ \\
\hline 11 & $27.82 .93(\mathrm{t}, 2 \mathrm{H}, J=7)$ & $\begin{array}{l}\mathrm{C} 10, \mathrm{Cl}, \mathrm{Cl} 3 \\
\mathrm{C} 17\end{array}$ & $\mathrm{H} 10, \mathrm{Hl} 3$ \\
\hline 12 & 125.7 & & \\
\hline 13 & $115.16 .67(\mathrm{~s}, 1 \mathrm{H})$ & $\mathrm{C} 14, \mathrm{Cl} 15, \mathrm{Cl} 17$ & $\mathrm{HIl}$ \\
\hline 14 & 146.2 & & \\
\hline 15 & 143.2 & & \\
\hline 16 & $113.26 .41(\mathrm{~s}, \mathrm{IH})$ & $\begin{array}{l}\mathrm{C} 12, \mathrm{Cl}, \mathrm{Cl} 5 \\
\mathrm{C} 18\end{array}$ & $\mathrm{H} 21, \mathrm{H} 25$ \\
\hline 17 & 118.3 & & \\
\hline 18 & 135.9 & & \\
\hline 19 & 114.2 & & \\
\hline 20 & 127.0 & & \\
\hline 21 & $117.46 .73(\mathrm{~d}, 1 \mathrm{H}, J=2)$ & $\mathrm{C} 22, \mathrm{C} 23, \mathrm{C} 25$ & $\mathrm{H} 9, \mathrm{HI} 6$ \\
\hline 22 & 147.0 & & \\
\hline 23 & 147.5 & & \\
\hline 24 & $112.97 .07\left(\mathrm{~d}, 1 \mathrm{H}_{,} J=8\right)$ & $\mathrm{C} 20, \mathrm{C} 22, \mathrm{C} 23$ & $\mathrm{H} 25, \mathrm{H} 26$ \\
\hline 25 & $121.26 .74(\mathrm{dd}, 1 \mathrm{H}, J=8,2)$ & $\mathrm{C} 19, \mathrm{C} 21, \mathrm{C} 23$ & $\begin{array}{l}\mathrm{H} 9, \mathrm{Hl} 6 \\
\mathrm{H} 24\end{array}$ \\
\hline 26 & $55.43 .88(\mathrm{~s}, 3 \mathrm{H})$ & $\mathrm{C} 23$ & $\mathrm{H} 24$ \\
\hline
\end{tabular}

All experiments were performed in DMSO-d 6 . Chemical shifts are reported in $\delta$ units (downfield of TMS). All ${ }^{1} J_{\mathrm{CH}}$ correlations were determined by HMQC experiments at $500 \mathrm{MHz} .{ }^{a 13} \mathrm{C}$ NMR was abtained at $50 \mathrm{MHz}$. "Spectra were acquired at $500 \mathrm{MHz}$.

or were para-positioned since there was no coupling among them.

In the HMBC spectrum of 1 , the proton signals at $\delta 7.07$ $(\mathrm{H} 24)$ and $6.73(\mathrm{H} 2 \mathrm{l})$ were coupled to both quatemary carbon signals at $\delta 147.0$ and 147.5. However, the carbon signal at $\delta 147.5$ only correlated to the proton signal $\mathrm{H} 25$ at $\delta 6.74$. Therefore. the carbon signal was assigned to $\mathrm{C} 23$. since ${ }^{4} J_{\mathrm{CH}}$ couplings were rarely observed in the HMBC experiments $(8 \mathrm{~Hz})$. The methoxy signal at $\delta 3.88$ also coupled to the carbon signal at $\delta 147.5$. Furthermore. a correlation between the methoxy signal and the proton signal $\mathrm{H} 24$ was observed in NOESY spectra. This allowed the position of the methoxy group to be assigned as $\mathrm{C} 23$. The carbon signal $\mathrm{Cl} 9$ at $\delta 114.2$ was long-range coupled to the proton $\mathrm{H} 25$ at $\delta 6.74$. which resulted in assigument of subunit A (Scheme 1).

Two protons $\mathrm{HI} 3$ at $\delta 6.67$ and $\mathrm{Hl} 6$ at $\delta 6.41$ were parapositioned since there was no coupling in the proton spectrum of 1 . The assignment of two hydroxyl groups at the 
<smiles>C/C=C(/C)c1ccc(OC)c(O)c1</smiles>

A

B most deshielded carbons at $\delta 143.6$ and 146.2 was supported by the up-field shifts of two adjacent carbon signals C.13 ( $\delta$ $115.1)$ and $\mathrm{Cl} 6(\delta 113.2)$. Initially. the carbon signal at $\delta$ 125.7 was assigned as any carbon within a three-bond range such as $\mathrm{C} 2 . \mathrm{Cl}$, or $\mathrm{C} 18$. The carbon signal gave two additional correlations to protons $\mathrm{Hll}$ 's $(\delta 2.93)$ and to proton $\mathrm{Hl} 6(\delta 6.41)$. Hence. the possibility of the carbon being $\mathrm{C} .18$ was eliminated again with the restriction of $\mathrm{HMBC}$ couplings within three-bond ranges. With a correlation of $\mathrm{Hl} 3$ ( $\delta$ $6.67)$ to $\mathrm{Cl}$ ( $\delta 118.3$ ). a dihydroisoquinoline moiety. subunit $\mathbf{B}$, was constructed.

From $\mathrm{HMBC}$ correlations by two para-positioned proton singlets at $\delta 6.72$ and 6.46 ( $\mathrm{H} 6$ and $\mathrm{H} 9$, respectively) and the ester functional group. suggested by IR $\left(1690 \mathrm{~cm}^{-1}\right)$ and the carbon signal at $\delta 154.4$, the subunit $\mathrm{C}$ was very obvious.

The last two connectivities, $\mathrm{C} 3-\mathrm{C} 19$ and $\mathrm{C} 18-\mathrm{C} 19$, were established based on NOESY correlations: $\mathrm{H} 9$ to $\mathrm{H} 21, \mathrm{H} 9$ to

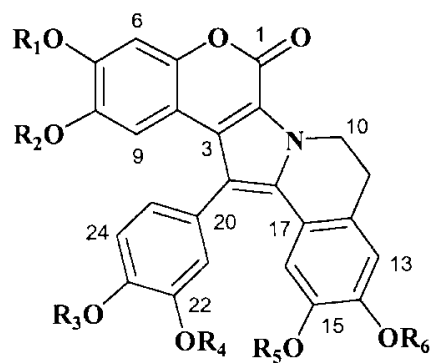

lamellarins

1. $\beta \quad R_{1}=R_{2}=R_{4}=R_{5}=R_{6}=I I, R_{3}=M e$

2. $\mathrm{G} \quad \mathrm{R}_{2}=\mathrm{R}_{4}=\mathrm{R}_{6 j}=\mathrm{H}, \mathrm{R}_{1}=\mathrm{R}_{3}=\mathrm{R}_{5}=\mathrm{Me}$

3. $\mathrm{L} \quad \mathrm{R}_{1}=\mathrm{R}_{4}=\mathrm{R}_{6}=\mathrm{II}, \mathrm{R}_{2}=\mathrm{R}_{3}=\mathrm{R}_{5}=\mathrm{Me}$

1a. $\beta$ acetate $R_{1}=R_{2}=R_{4}=R_{5}=R_{6}=A c, R_{3}=M e$

Figure 1. Lamellanns and a denvative. Brosynthetically, the compounds appear to be derived from the condensation of three DOPA molecules. ${ }^{12}$ The numbering system for the lamellarins used in this study is different from that in previous studies because it is designed to illustrate their relatedness to other DOPA-alkaloids isolated from Didenmmm species.
$\mathrm{H} 25, \mathrm{H} 16$ to $\mathrm{H} 2 \mathrm{l}$. and $\mathrm{H} 16$ to $\mathrm{H} 25$. The large difference in chemical shift between $\mathrm{C} 2(\delta 112.2)$ and $\mathrm{C} 3(\delta 127.5)$ could be rationalized if $\mathrm{C} 2$ and $\mathrm{C} 3$ were $\alpha$ and $\beta$ to the ester carbonyl Cl $(\delta$ 154.4). The overall data explained the 18 unsaturations inherent in the molecular formula. Therefore. the structure was proposed as $\mathbf{1}$ shown in Figure 1.

Chiratity of Molecule. As implied in the NOESY experiment of 1 , the catechol ring at C 19 was predicted to be almost orthogonal to the rest of the molecule from molecular modeling study to avoid severe steric interactions. Due to the proximity of the coumarin and the isoquinoline moieties. free rotation of the catechol ring at $\mathrm{C} 19$ is seriously restricted. The rotational barrier of the bond between $\mathrm{C} 19$ and $\mathrm{C} 20$ was in excess of $80 \mathrm{Kcal} / \mathrm{mole}$. Due to the highly restricted rotation of the catechol ring, the molecule could be cliral. However. all lamellarins isolated in this study were racemic as observed before in previous studies, ${ }^{3.8,15.11}$ which suggested thermal racemization to be a facile process. ${ }^{s}$ One of the lowest energy foms. as illustrated in space-filling model, is presented in Figure 2.

Shielding Effect of Phenyl Ring at C19. The pseudoorthogonal conformation of the catechol ring at C19 generated significant proton NMR shielding effects of two protons $\mathrm{H} 9$ ( $\delta$ 6.46) and $\mathrm{Hl} 6$ ( $\delta$ 6.41). Their up-field shifts, compared to other proton signals $\mathrm{H} 6(\delta 6.72)$ and $\mathrm{HI} 3(\delta$ 6.67 ). were induced by diamagnetic anistropy of the catechol ring at $\mathrm{C} 19^{\text {?i }}$

In conclusion. we identified a novel cy totoxic compound. lamellarin $\beta$. along with previously reported lamellarins $G$ and $\mathrm{L}$. from an unidentified species of marine ascidian Didemmim. Due to the steric crowding the alkaloid was predicted to have a catechol ring pseudo-orthogonal to the rest of the molecule. Yet the compound did not show chirality which indicated thermal racemization to be a facile process. The new compound was tested for cytotoxicity

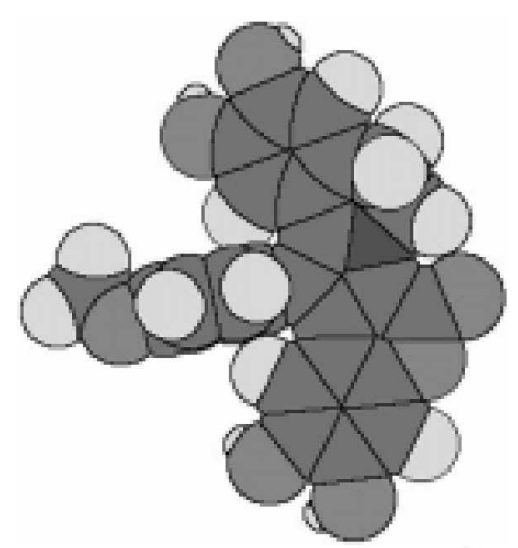

Figure 2. Computer-generated perspective drawing of one of the lowest energy fonms for the lamellarin $\beta$. The pseldo-orthogonal contormation of the catechol at C 19 gave significant shelding effects to the two protons $\mathrm{H} 9$ and $\mathrm{HI} 6$ in the proton NMK spectrum of lamellarin $\beta$. The catechol ring was 74 degrees out of the plane of the pyrrole nng since the isoquinoline ring was twisted about 20 degrees. The coumann molety and the pyrole nng were perfectly co-planar. 
against various human tumor cell lines in culture. Lamellarin $\beta$ showed cytotoxicity against human pronlyelocytic leukemia $\mathrm{HL}-60$ with an $\mathrm{IC}_{50}$ of $4.8 \mu \mathrm{g} / \mathrm{mL}$. The cytotoxicity of lamellarin $\beta$, compared to that of the ethyl acetate-solubles $\left(\mathrm{IC}_{5 \mathrm{Si}}=4.8 \mu \mathrm{g} / \mathrm{mL}\right.$ ). suggested more active compounds yet to be identified. We are currently investigating more potent compounds from this ascidian.

Acknowledgment. We thank Professor William Fenical for generously providing animals used in this work. This research is a result of funancial support from the Ministry of Health and Welfare. Republic of Korea. under a grant of the Korea Health 21 R\&D Project (HMP-00-CD-01-0001), and in part from the SNU Research Fund and the Ministry of Education, Republic of Korea. under BK2I Progran.

\section{References}

1. Davidson. B. S. Chemt. Rev: 1994.93.1771.

2. Faulkner. D. J. Nat. Prod. Rep. 2001. I8. 1.

3. Anderson, R. J.; Faulkner, D. J.: Cun-heng. H.: Van Duyine, G. D.: Clardv. J. J. Am. Chem. Soc. 1985, 107, 2492.

4. Lindquist. N.: Fenical, W: Van Duyne, G. D.: Clardy, D. J. Org. Chem. 1988. 53.4570 .

5. Davis. R. A.: Carroll. A. R.: Pirens. G. K.: Quints. R. J. J. Nat. Prod 1999.62.419
6. Urban. S.; Butler. M. S.; Capon. R. J. Atust. J. Chem. 1994. 47. 1919.

7. Urban1. S.: Hobbs. L.: Hopper. J. N. A.: Capon1. R. J. Alust. J. Chent 1995. 48. 1491.

8. Carroll, A. R.: Bowden, B. F. Coll. J. C. Atust J. Chem. 1993. 46. 489.

9. Urban. S: Capon, R. J. Atust. J. Chem. 1996, 49,711.

10. Reddy. M. V. R.: Faulkner. D. J.: Venkateswarlu. Y: Rao. M. R. Tetrahedron 1997.53.3457.

11. Reddy. M. V. R.: Rao. M. R.: Rhodes. D.: Hansent. M. S. T.: Rubins. K. Bushman, F. D.: Venkateswarlu, Y; Faulkner, D. J. Hed Chem 1999, +2, 1901.

12. Kang, H.; Fenical, W. J. Org. Chem 1997, 62, 3254.

13. Quesada. A. R.: Gravalos. M. D. G.: Puentes. T. L. F. Br. J. Cancer 1996. 7t.677.

14. Boger. D. L.: Boyce. C. W.: Labroli. M. A.: Sehon. C. A.: Jin. Q. J. Am. Chem. Soc. 1999. 121, 54

15. Piantini, U.: Sorensen, W.: Enst, R. R. J. Am. Chem. Soc, 1982. 104. 6800

16. Doddrell. D. M.: Pegg. D. T.: Bendall. M. R. J. Magn. Reson. 1982. +8.323

17. Bax. A.: Drobny. G. J. Magrt. Reson. 1985.61. 306.

18. Bax. A.; Summers, M. F. J. Am. Chem. Soc. 1986, 108. 2093.

19. Mosmann, T. J. Inmunol Wethods $1983,65,55$

20. Jackman. L. M; Sternhill, S. Applications of Niclear Magnetic Resonance Spectroscopy in Organic Chentistry: Pergamon Press: Osford. U. K.. 1969: p 61. 